The Journal of Air Transport Studies (JATS - ISSN: 1791-6771) is a peer reviewed journal aiming at publishing high quality research related to air transport. JATS is interested in publishing papers primarily focusing on economics, geography, policymaking, management, marketing, operations, technology, logistics/supply chain management and modelling.

The J ournal is published electronically twice a year, i.e. in J anuary and J uly by the Hellenic Aviation Society (www.aviationsociety.gr). The January issue usually contains papers (subject to changes) originally presented at the Air Transport Research Society (www.atrsworld.org) Conference of the previous year(s) whereas the July issue may be occasionally dedicated to a special theme. The Journal is accessible online free-of-charge.

J ournal of Air Transport Studies (J ATS)

(c) Hellenic Aviation Society

12, Agiou Charalambous Street, Athens 114 74, Greece.

Telephone: +302106424 401

Facsimile: +302106424 401

Website: http://www.aviationsociety.gr

Volume 4, Number 2, Summer 2013, ISSN: 1791-6771. 


\section{Editorial and Advisory Board}

- Editor-in-Chief: Dr Andreas Papatheodorou, Hellenic Aviation Society and University of the Aegean, Greece

- Associate Editor: Dr Kostas Iatrou, Hellenic Aviation Society, Greece

- Assistant Editor: Dr Zheng Lei, Cranfield University, United Kingdom

- Book Reviews Editor: Mr Pavlos Arvanitis, University of the Aegean, Greece

- Conference Reports Editor: Ms I oulia Poulaki, University of the Aegean, Greece

- Honorary Advisor: Dr Taieb Cherif, Former ICAO Secretary General

- Scientific and Advisory Board

- Professor Larry Dwyer, University of New South Wales, Australia

- Professor Peter Forsyth, Monash University, Australia

- Professor Sveinn Gudmundsson, Toulouse Business School, France

- Professor Hans-Martin Neimeier, University of Applied Sciences Bremen, Germany

- Professor Tae Oum, President of ATRS, University of British Columbia, Canada

- Professor Paris Tsartas, University of the Aegean, Greece

- Professor Respicio Espírito Santo, Rio de Janeiro Federal University, Brazil

- Professor Pauline Sheldon, University of Hawaii, USA

- Professor Anming Zhang, University of British Columbia, Canada

- Professor Evangelos Christou, Technological Institute of Thessaloniki, Greece

- Dr Leonardo Corbo, LUISS Guido Carli University, Italy

- Dr Anderson Correia, Instituto Tecnológico de Aeronáutica, Brazil

- Dr Dimitrios Dimitriou, Cranfield University, United Kingdom

- Dr Rafael Echevarne, $\mathrm{ACl}$, Canada

- Dr Triant Flouris, Hellenic American University, Greece

- Dr Anne Graham, University of Westminster, United Kingdom

- Dr Paul Hooper, Department of Transport, Abu Dhabi, UAE

- Dr Panagiotis Karamanos, Athens International Airport, Greece

- Dr Eleftherios Katarelos, Hellenic Civil Aviation Authority, Greece

- Dr Tay Ryang Koo, University of New South Wales, Australia

- Dr Konstantinos Kostopoulos, Hellenic Competition Commission, Greece

- Dr Gui Lohmann, Southern Cross University, Australia

- Dr Christos Markou, IATA, Canada

- Dr Keith Mason, Cranfield University, United Kingdom

- Dr John F. O' Connell, Cranfield University, United Kingdom

- Dr Marianna Sigala, University of the Aegean, Greece

- Dr Dimitrios Stergiou, Hellenic Open University, Greece

- Dr Bijan Vasigh, Embry-Riddle Aeronautical University, USA

- Captain Spyros Jancovich, Hellenic Aviation Society, Greece

- Mr Takis Adamidis, Hellenic Aviation Society, Greece

- Mr Mario Diaz, Atlanta International Airport, USA

- Mr Panagiotis Grigoriou, Hellenic Aviation Society, Greece

- Mr Emmanuel Gyzis, Emm. A. Gyzis \& Partners Law Offices, Greece

- Mr Ray Kaduck, Canadian Transportation Agency, Canada

- Mr Emmanuel Keramianakis, Hellenic Aviation Society

- Mr Antonios Simigdalas, Independent Aviation Consulting, Cyprus

- Ms Narjess Teyssier, ICAO, Montreal

- Mr Stamatis Varsamos, Athens International Airport, Greece

- Mr David Young, Eurocontrol, France 


\section{Notes for Contributors}

JATS publishes the following categories of papers written in scholarly English: a) Full Research Papers, b) Conference Reports, c) Book Reviews, d) Industry Perspectives. Papers should be submitted electronically to a.papatheodorou@aegean.gr in MS-Word format ONLY using British spelling, single-column, 1.5 line spacing, Tahoma letters, font size 11. Section headings (and sub-headings) should be numbered and written in capital letters. Upon acceptance of a paper and before its publication, the corresponding author will be asked to sign the Transfer of Copyright form on behalf of all identified authors.

Full Research Papers should contain original research not previously published elsewhere. They should normally be between 4,000 and 7,000 words although shorter or lengthier articles could be considered for publication if they are of merit. The first page of the papers should contain the title and the authors' affiliations, contact details and brief vitae (of about 50 words). Regarding the following pages, papers should generally have the following structure: a) title, abstract (of about 150 words) and six keywords, b) introduction, c) literature review, d) theoretical and/or empirical contribution, e) summary and conclusions, f) acknowledgements, g) references and h) appendices. Tables, figures and illustrations should be included within the text (not at the end), bear a title and be numbered consecutively. Regarding the referencing style, standard academic format should be consistently followed. Examples are given below:

- Airbus (2003), Global Market Forecasts 2003-2022, Toulouse: Airbus.

- Fragoudaki, A., Keramianakis, M. and Jancovich, S. (2005) The Greek PSO Experience. $4^{\text {th }}$ International Forum on Air Transport in Remoter Regions. Stockholm, May 24-26.

- Forsyth P. (2002a), 'Privatization and Regulation of Australian and New Zealand Airports', Journal of Air Transport Management, 8, 19-28.

- Papatheodorou, A. (2008) The Impact of Civil Aviation Regimes on Leisure Market. In Graham, A., Papatheodorou, A. and Forsyth, P. (ed) Aviation and Tourism: Implications for Leisure Travel, Aldershot: Ashgate, 49-57.

- Skycontrol (2007) easyj et welcomes European Commission's decision to limit PSO abuse in Italy. $23^{\text {rd }}$ April. Available from: http://www.skycontrol.net/airlines/easyjetwelcomes-european-commissions-decision-to-limit-pso-abuse-in-italy/ (accessed on 22/08/2008). 
Conference Reports should be between 1,000 and 1,500 words. They should provide factual information (e.g. conference venue, details of the conference organizers), present the various programme sessions and summarize the key research findings.

Book Reviews should be between 1,000 and 1,500 words. They should provide factual information (e.g. book publisher, number of pages and ISBN, price on the publisher's website) and critically discuss the contents of a book mainly in terms of its strengths and weaknesses.

Industry Perspectives should be up to 1,000 words and provide a practitioner's point of view on contemporary developments in the air transport industry. Contributors should explicitly specify whether their views are espoused by their organization or not. 


\section{Table of Contents}

EDITORIAL. ..vii

Andreas Papatheodorou, Kostas Iatrou and Zheng Lei

Full Research Papers

1. ECONOMIES OF SCALE AND SCOPE OF AIRPORTS - A CRITICAL SURVEY 1 Malte Lechmann and Hans-Martin Niemeier

The question whether airports are natural monopolies has increasingly become an issue in studies on regulation, deregulation and privatization of airports. In particular it was questioned whether airports have market power at all and if this is due to economies of scale and scope. This paper provides an overview of studies on economies of scale and scope. It critically evaluates the method of data gathering during the studies and the resulting information uncovers some drawbacks of the studies and the data gathering process. It reaches the conclusion that the most studies on economies of scale are problematic in regard to the definition of "output", the treatment of capital and the exclusion of land side activities. Economies of scope have only been researched in the most recent studies. The study illustrates that the non-aviation business should be considered in more detail.

2. AIRPORT SECURITY: CURRENT PRACTICE AND PERSPECTIVES FOR 2030. 26 Samson Fatokun

The high profile of aviation has made it an attractive target to terrorist activities. The September 11 terrorist attack and subsequent failed terrorist attacks made safety and security top priorities for the aviation industry. A review of the current practice in airport security conducted by the author found that it was reactive, expensive and inefficient in some areas based on a "one-size-fits-all" principle. The forecast of a new approach to airport security conducted in this study predicted that by 2020 2030 airport security will be proactive and based on passenger differentiation.

3. EVALUATION AND SELECTION OF A FLEET OF AIRCRAFT LOCATED IN MADNIAH, SAUDI ARABIA .

Wail I. Harasani

The present work simulates the evaluation and selection of a fleet of aircraft for a proposed airline located in Madniah, Saudi Arabia, to operate across an assumed network that includes both local and international destinations. This simulation is 
conducted through a series of phases and subsequent deeper and meticulous levels of analysis. At the end of these phases some recommendations are given for selecting the suitable fleet. The phases are simulated using MS Excel and the output of the study predicts both the aircraft efficiency and its contribution to the net profit of the airline. Considering the destination ranges covered within the network and such other important criteria as the respective payloads, a number of candidate aircraft were chosen for the study. Finally, it was found from the study that 5 of the EMB170 aircraft would be the best choice for the proposed airline.

4. AVOIDING THE PREDICTABLE SURPRISE: EARLY ACTION IS THE KEY TO BUILDING A CLIMATE-RESILIENT AVIATION NETWORK .54 Rachel Burbidge

Impacts of climate change, such as sea level rise, higher temperatures and greater weather extremes create an operational, financial and business risk for European aviation. However these are risks which the sector can work to avoid by taking early, and cost-effective, action. A growing but limited number of stakeholders are already implementing comprehensive resilience measures. Yet, a survey of European aviation organisations shows that although awareness is growing many stakeholders are still not acting, often due to a lack of information and guidance. Five key recommendations have been developed to promote cost-effective climate resilience within the sector. These include local and network-wide risk assessment, better use of MET information and the implementation of 'no-regrets' or 'win-win' measures which also address issues such as capacity. Overall, climate change is an issue of risk management and early action is the key to cost-effective mitigation of those risks. 


\section{Editorial}

This issue of the Journal of Air Transport Studies includes four papers.

Lechmann and Niemeier provide a critical overview of the air transport literature on economies of scale and scope concluding that the majority of studies are problematic with respect to the definition of "output", the treatment of capital and the exclusion of land side activities. In another paper, Fatokun reviews the current practices in airport security concluding that there are reactive, expensive and inefficient in some areas based on a "onesize-fits-all" principle. The paper argues in favour of pro-activeness based on passenger differentiation.

In the following contribution, Harasani simulates the evaluation and selection of an aircraft fleet for a proposed airline located in Madniah, Saudi Arabia, to operate across an assumed network that includes both local and international destinations. The paper suggests that the EMB170 aircraft would be the best choice for the proposed airline. Finally, Burbidge studies the impact of climate change on aviation making five key recommendations on how to develop a framework of cost-effective climate resilience within the sector: climate change is an issue of risk management and early action is the key to cost-effective mitigation of those risks.

May we take this opportunity to thank all our authors and referees for their support in publishing this eighth issue of the Journal. Our continuing partnership with Air Transport News in conjunction with the open access character of the journal aim at ensuring that J ATS can get a significant exposure to the academic and business audience and raise its profile accordingly. Enjoy reading!

Dr Andreas Papatheodorou, Editor-in-Chief

Dr Kostas latrou, Associate Editor

Dr Zheng Lei, Assistant Editor 